\title{
Study on the Construction of Scientific Research Funding Supervision System in Colleges and Universities \\ - Based on internal control perspective
}

Shuo Wang

Bohai University

\section{Keywords: Expenditure Supervision; Internal Control; Management Coordination}

\author{
Abstract. In recent years, the country has invested more and more scientific research funding, and \\ the effective use of
}

them have been paid more and more attention by all sectors of society. Based on the relationship between internal control and the supervision of university scientific research funding, this paper constructs the framework of university expenditure supervision system based on internal control, to strengthen the internal control to standardize the economic activities of colleges and universities and improve the modern management level of colleges and universities.

In recent years, as the country has increased investment in education funding for colleges and universities, and with the continuous scale expansion of higher education, the management work for using scientific research funding of colleges and universities is increasingly urgent and complex. On the one hand, the investment of our country in colleges and universities continues to increase; on the other hand, the level of management for the use of these funding within the university does not "rise", corruption incidents in colleges and universities are still ongoing, and irregularities are also frequent, which not only causes economic losses to the universities and the country, but also forms negative impact in the society. Therefore, for the supervision of scientific research funding in colleges and universities, it is necessary to strictly take actions to avoid risks fundamentally, standardizing the use of scientific research funding, improving the efficiency of them, to improve the modern management level of colleges and universities.

\section{The Relationship between Internal Control and Supervision of Funding in Colleges and Universities}

The management of research funding involves a series of work links, including the self-quality and morality of the users and their behavior and motivation. In the management process of scientific research funding, self-discipline is the first barrier to supervise. However, the self-discipline referred to here is not only the moral level, legal concept and morality of users as generally understood, but also refers to self-discipline of the university itself, and the self-discipline of the university itself relies onthe construction level ofits own internal control system, the more perfect internal control system, the supervision of scientific research funding will become more effective, and the risk of corruption and dereliction of duty will become lower.

\section{Healthy Internal Control Environment is the Basis of Scientific Research Funding Supervision}

Self-discipline of the research funding users depends on their individual moral level, and it is necessary to develop with a long-term training process of propaganda, education and environment. But for colleges and universities, self-discipline of the unit can be improved by strengthening the internal management, perfecting their own internal control system. If there is no sound internal 
control system, no matter how good the research funding regulatory measures are, they can only be a temporary solution. Therefore, the perfect internal control system is the foundation to strengthen the scientific research funding supervision and management. Through establishingand perfecting from scientific research funding collection to the allocation, usage and performance evaluation, strengthen from all aspects of the development of internal control measures, so that internal control measures can penetrate intoeach stage of the university research funding supervision, making funding users have no chances in order to effectively restrain the behavior of the users, to make the use of research funding achieve maximum efficiency.

\section{Sound Internal Control Measures are the Guarantee to Improve the Efficiency of Scientific Research Funding}

As non-profit organizations, the main responsibility of colleges and universities is to teach and educate people, train professionals for the country and society, andserve scientific research. The use of research funding should also follow this purpose. The target of research funding is to assist research tasks. Its use should achieve corresponding performance objectives, putting the limited scientific research funding in the place, giving full play to its due role, to promote the sustained and healthy development of education. The relevant management departments of scientific research funding in colleges and universities should perfect the incentive mechanism and accountability mechanism to improve the efficiency of running benefits by establishing the performance evaluation indicators for fund expenditure. The sound internal control system not only plays an important role in the sustained and healthy development of colleges and universities, but also is an important guarantee to improve the efficiency of colleges and universitiesfunding.

The Establishment of Internal Control System is the Basis to Improve the Level of Management of Colleges and Universities Funding

It is of great significance to establish a sound and effective internal control system to improve the management level of scientific research funding and standardize the economic order of colleges and universities. Under the situation that the country continues to increase investment in colleges and universities research funding, there will be inevitably the phenomenon violating disciplinary, resulting in unstandardized and unreasonable use of scientific research funding. There will also be phenomenon with false invoices withdrawing cash. In order to curb the further development of such behaviors, the regulation of using scientific research funding from the perspective of internal control is considered as the most effective way. Therefore, colleges and universities should not only strengthen the education of clean government, implement strict financial discipline, but also improve the internal control system and the management level of scientific research funding, reducing the risk from the root causes to ensure completing the work of colleges and universities normally.

\section{The Problems in the Supervision of Scientific Research Funding in Colleges and Universities}

\section{The Supervision Mechanism is Imperfect and Lack of Accountability.}

There are two major problems in the supervision of scientific research funding:

(1) At present, China has not set up relevant systems and auditing methods for the management of scientific research funding in colleges and universities. There is no real-time follow-up supervision on the expenditure of funding. In most cases, before the audit, universities will make up deficiency for corresponding expenditure for scientific research activities, which is a remedy, and leads to that the problem are not solved in the best period.

(2) Many people mistakenly believe that the use of scientific research funding is only a financial issue, which ignores the important role of supervision of various functional departments in using 
scientific research funding, leading to the links between functional departments are not close. Science and technology departments are only concerned about the project, but ignore the process of tracking the project; and the financial department focuses on the final settlement, without fully considering budget indicators; the audit department staff do not involve in the audit actively. The relevant functional departments lack of mutual communication and cooperation that cannot form a whole tracking for the use process of scientific research projects funding, which also leads to the management of scientific research funding cannot be reasonable and efficient. At present, the accountability system in the field of education in China is mainly the reporting system. There is no clear stipulation on the accountability system of scientific research funding management, which makes the design of performance evaluation index of colleges and universities less scientific, the performance evaluation procedure is not standardized, and each link of evaluation is not harmonized. Most colleges and universities do not realize that it can better play the role of performance evaluation to improve the scientific research funding accountability system. For the most colleges and universities, there is no perfect system for accountability about if all the scientific research funding is fully used in projects, which makes the performance evaluation of using scientific research funding be only a statement of form without any practical significance.

\section{Information Asymmetry Leading to Poor Regulatory Efficiency}

China's university organization system is bureaucracy, that is, school-level leadership is at the top of power. They exercise the authority through the transmission to lower level. The advantage of this organization system is that order maintenance can maintain a high degree of unity, but at the same time there are defections. For example, in the supervision and management of scientific research funding, the management chain is long with many levels from the school level to the rank of section chief, administrative rank of section or department, then to the basic level staff, at least through four levels. If coupled with the vice president, vice director, it will go through six levels. Such a long management chain is bound to affect the accuracy and efficiency of information transmission, but also increase the difficulty of coordination between organizations, affecting the transmission of information.

With the development of society, the current form of economic activity is increasingly abundant and the carrier is more diversified. There is more and more integration between colleges and universities and the society. In the era of large data, the information acquisition, transmission, and use go throughout the supervision work of scientific research funding. But the current bureaucratic system leads to management information can only be passed up and down in a channel. The problems, difficulties and some important information found in the process of funding supervision are difficult to transfer timely, which greatly affects the efficiency of information transmission, and directly resulting in lower efficiency of regulation.

The Regulatory Pressure and Risk are Negatively Correlated and the Risks cannot be Effectively Controlled.

In terms of bureaucratic system, from the top level of regulatory organization to the basic level of regulatory activities, the responsibility is reduced with level, so is the pressure. The middle and senior managers in colleges and universities bear a huge responsibility and pressure, but the main regulatory activities and risk prevention and control are reflected in the specific business activities, which requires the effective supervision of grassroots staff to achieve. As a result, the leadership level needs to bear higher regulatory pressure, but the risks and responsibilities cannot match for the grassroots staff, which can easily lead to losing control of the risks. The focus of financial supervision should be at the grassroots level. Only if the pressure of supervisory responsibility can be transmitted to the lower levels, grassroots regulators can pay more attentions to the risk 
prevention and control, their awareness of risk is raised, their sensitivity of risk is enhanced, as well as the risk prevention and control ability is improved, the risk can be ultimately controlled and resolved.

\section{The Construction of Scientific Research Funding Regulatory System Based on the Internal Control}

\section{Objective of Colleges and Universities Financial Supervision}

As a nonprofit organization that provides public service products to the society, the daily operation of colleges and universities mainly depends on the funds to maintain. Therefore, the rational use of funds is the primary task of financial management in colleges and universities. The objective of financial supervision in colleges and universities must obey and serve the objective of financial management, which has the advantages of minimizing the cost and maximizing the efficiencyof running colleges, optimizing the allocation of resources, making full use of resources, diversifying measures and channels, as well as rationalizing the allocation of funds. The objective of financial supervision in colleges and universities is to ensure the safe, standardized and effective use of funds by strengthening the supervision of using funds in colleges and universities. It can be seen that the objective of funding supervision in colleges and universities is the same as their financial management objective.

(1) Security

The most basic objective of funding supervision in colleges and universities is the safety. To ensure the safety management of funding, especially in the links of financing, distribution and use, colleges and universities need to conduct full supervision, in order to implement their financial discipline strictly, to avoid property damage and prevent economic crime from the source. The responsible persons in each school and the person in charge of the project are listed as the first person responsible for the management of funding, in accordance with the requirements of the rule of "responsible signature" and the economic responsibility system, strict liability system is implemented. For those who waste of funds and loss personnel due to mismanaged actions, lax control should be investigated and affixed the responsibility. In addition, the funding review system and prevention mechanisms should be established and completed for risk assessment of funding use in each step, and the corresponding measures will be set to ensure the safety management of funding and prevent financial fraud. By strengthening the supervision for using funding and clean government construction, enhancing the regulation of cost and bills, strictly exercising "two lines of revenue and expenditure", severely punishing the "small treasury" and "extra account" funding will be prevented from being diverted or retained.

(2) Compliance

Sound funding management system that is easy to implement is the premise of standardized use of funding. In order to ensure the standardized use of funding, the management of funding must comply with relevant state laws, regulations and rules. Colleges and universities should take use of the opportunities of modern university system and improving the internal management structure, to streamline their funding management process, in conjunction with the actual situation of the colleges and universities, in accordance with relevant laws and regulations and systems, the refined and complete enforcement regulation of management of funding with pertinence is developed. In addition, they need to be revised and perfected according to the changes of national policy to ensure that the funding management system and process can be complemented and strengthen the publicity and training of funding management system, to establish a system framework and implementation mechanism that conforms to the modern university model. 
(3) Performance

To achieve the ultimate objective of cultivating talents and developing scientific research, the country will invest funding to the construction of teachers and disciplines in colleges and universities, as well as international exchanges and cooperation to promote the vigorous development of higher education. The funding management department of colleges and universities should establisha performance evaluation system through the establishment and improvement of the system of reward and punishment, and carry out the performance concept in the process of funding management, so that the limited funds can give full play to the role of "offering fuel in snowy weather", spending wisely on good to improve the effectiveness of funding regulation, to maximize the efficiency of using funding.

\section{References}

[1] Zhang Shaochun. Implementation of Internal Control Norms, to Create "Upgraded Version" of Administrative Institutions Management. China Accounting News, 2013-07-26

[2] Wang Chunju, Lu Qiuping.Study on the Framework Design of Funding Supervision System of China's Colleges and Universities. Journal of Sichuan Normal University, 2014 (03)

[3] Shu Lianzhi. Study on the Contents of Industrial Audit in Colleges and Universities. Journal of Wuhan University of Technology, 2007 (04)

[4] Lei Yangkun. Exploration onHigher Education Funding Regulatory Path in New Era.Education Accounting Research.2013, (5)

[5] Li Haitao, Tu Lei. Reflections on the Management System and Operation Mechanism of Scientific Research Funding in Colleges and Universities. Friends of Accounting, 2013 (12) 